\title{
Acute Spinal Pain During an Attempted Lumbar Epidural Blood Patch in Congenital Lumbar Spinal Stenosis and Epidural Lipomatosis
}

\author{
W. Michael Hooten, MD, Michael S. Hogan, MBBCh, Thomas C. Sanemann, MD,
} and Timothy J. Maus, MD

From: Department of Anesthesia, Mayo Clinic, Rochester, MN

Dr. Hooten is Assistant Professor, Mayo Clinic College of Medicine, Department of Anesthesiology. Dr. Hogan is with the Mayo Graduate School of Medicine, Department of Anesthesiology. Dr. Sanemann is with the Mayo Graduate School of Medicine, Department of Anesthesiology. Dr. Maus is with the Mayo Clinic College of Medicine,

Department of Radiology.

Address correspondence W. Michael Hooten, MD Assistant Professor Department of Anesthesiology Mayo Clinic College of Medicine 200 First Street SW

Rochester, MN 55905

E-mail: hooten.william@mayo.edu

Disclaimer: There was no external funding in the preparation of this manuscript. Conflict of interest: None.

Manuscript received: 07/20/2007 Revisions received: 11/01/2007 Accepted for publication:11/06/2007

Free full manuscript: www.painphysicianjournal.com
Congenital lumbar spinal stenosis is an uncommon condition that is often asymptomatic in young adults. Herein, we document the first reported occurrence of acute radicular back pain and associated congenital lumbar spinal stenosis in a healthy 24-year-old woman undergoing an epidural blood patch for treatment of a post-dural puncture headache related to an accidental dural puncture sustained during placement of a labor epidural catheter.

The acute pain symptoms were elicited twice with injection of less than $1 \mathrm{~mL}$ of fluid into the epidural space during the fluoroscopically assisted epidural blood patch. Subsequent magnetic resonance imaging of the lumbar spine demonstrated shortened pedicle length consistent with severe congenital lumbar spinal stenosis and prominent epidural fat. We speculate that the transient increase in pressure within the epidural compartment following injection of a small amount of fluid could have compressed neural structures resulting in severe radicular pain. The prominent epidural fat could have prevented rapid disbursement of the injected fluid which could have further served to propagate the pressure increase throughout the epidural compartment.

The unique radiographic features of congenital spinal stenosis could predispose some patients with this unrecognized condition to develop acute pain upon injection of a small amount of fluid into the epidural compartment. Unrecognized congenital lumbar spinal stenosis is an important addition to the differential diagnosis of acute radicular pain elicited during an epidural blood patch in previously asymptomatic patients.

Key words: Epidural blood patch, congenital spinal stenosis, epidural lipomatosis, acute spinal pain

Pain Physician 2008; 11:1:87-90

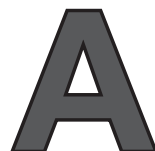

ccidental dural puncture(ADP) is a recognized complication of epidural analgesia for labor with a reported incidence of $0.19-3.6 \%$ (1). Eighty percent of patients may go on to develop a post-dural puncture headache (2). Generally, the symptoms of a post-dural puncture headache are believed to result from persistent loss of cerebral spinal fluid that contributes to postural sagging of the brain and traction on pain sensitive structures within the cranium. For patients who fail medical management, an epidural blood patch (EBP) is an effective and safe treatment option with few reported complications (3). Herein, we present a case report of a healthy 24 yearold woman who developed acute spinal pain during a fluoroscopically assisted lumbar epidural blood patch where after magnetic resonance imaging (MRI) revealed severe congenital lumbar spinal stenosis and lumbar epidural lipomatosis. 


\section{Case Report}

A healthy 24-year-old woman (gravida two, para one) presented at 36 weeks gestational age with premature onset of labor. The patient's body mass index upon admission was $25.8 \mathrm{~kg} / \mathrm{m} 2$. Intravenous medications were used to provide labor analgesia for the patient's first spontaneous vaginal delivery. She had no history of acute or chronic spinal pain. Following informed consent, labor epidural analgesia was initiated. The patient was placed in the sitting position and the skin over the lumbo-sacral area was cleansed with a sterile chlorhexidine solution. Sterile drapes were applied. A 3.5-inch, 18-gauge Hustead needle was placed into the L3-4 interspace using a midline approach. At approximately $7.5 \mathrm{~cm}$ there was an equivocal loss of resistance to normal saline using a glass syringe. The patient reported no pain with loss of resistance. A sterile epidural catheter was threaded $3 \mathrm{~cm}$ and aspiration revealed continuous flow of clear fluid consistent with cerebral spinal fluid. A single epidural dose of $3 \mathrm{~mL}$ of $1.5 \%$ lidocaine with epinephrine (1:200,000; $5 \mathrm{mcg} / \mathrm{mL})$ was injected. Within 3 minutes, development of bilateral lower extremity sensorimotor deficit to a dermatomal level of T8 confirmed intrathecal catheter placement. The catheter remained at $3 \mathrm{~cm}$ within the intrathecal space and was secured with sterile dressing. The patient subsequently underwent artificial rupture of membranes and progressed to have a normal, spontaneous vaginal delivery. The intrathecally sited catheter was removed intact 1 hour following delivery without pain or paresthesia.

Within 12 hours of delivery, the patient began reporting positional headache and neck pain consistent with a post-dural puncture headache. She described the headache as starting in the cervical region and extending to involve the entire cranium. The pain symptoms resolved in the recumbent position. Over the next 4 days, the headache and neck pain did not improve despite conservative measures including intravenous hydration, intravenous caffeine, oral nonsteroidal anti-inflammatory medications, and oxycodone as prescribed by the primary inpatient obstetric service. On physical examination, the patient was calm and there was no lumbar paraspinal tenderness or erythema at the catheter insertion site. Following informed consent, a fluoroscopically guided epidural blood patch was performed. The patient was placed in the prone position and the L3-4 interspace was identified by fluoroscopy. The skin was prepared with betadine, sterile drapes were applied, and the skin was anesthetized with $1.5 \%$ lidocaine. An 18-gauge Tuohy needle was advanced under fluoroscopic guidance. At our institution, epidural blood patches are performed with fluoroscopic guidance in an attempt to avoid unrecognized aberrant administration of the injectate (4). Simultaneous with loss of resistance to $1 \mathrm{~mL}$ of normal saline at approximately $7.5 \mathrm{~cm}$, the patient experienced the sudden onset of severe pain extending from the lumbar region to the coccyx. The pain resolved within 1 minute. Midline needle position was confirmed with anteroposterior and lateral fluoroscopic views and needle aspiration for cerebral spinal fluid was negative. There was no evidence of subdural contrast spread. Following resolution of pain, slow injection of contrast material demonstrated epidural spread, however, less than $1 \mathrm{~mL}$ of contrast material resulted in a similar brief episode of severe pain. Needle position was again confirmed with anteroposterior and lateral fluoroscopic views. Due to the pain symptoms, the needle was removed and the procedure was aborted.

An MRI of the lumbar spine was performed the following day. This revealed spinal stenosis throughout the lumbar spine due to a combination of short pedicles and prominent epidural fat (Figs. 1 and 2). The mean cross-sectional area of the spinal canal was $223 \mathrm{~mm} 2$ and the mean pedicle length was $5.8 \mathrm{~mm}$. The mean cross-sectional area of the thecal sac was 77 $\mathrm{mm} 2$. An area of reduced T2 signal at the L2 level was consistent with air related to the previously attempted epidural procedure performed at the L3-L4 level. No focal epidural hematoma or abscess was identified. Other findings included mild L5-S1 disc space desiccation. The patient was followed for the next 3 days in the hospital where conservative management, emphasizing recumbency, continued with improvement in the post-dural puncture headache symptoms. No residual spinal pain was reported during the remainder of the hospital course. Attempts to contact the patient after hospital dismissal were unsuccessful.

\section{Discussion}

To the authors' knowledge, this is the first reported case of congenital lumbar spinal stenosis, epidural lipomatosis, and associated acute pain during an attempted EBP. The anatomical anomalies identified on the lumbar spine MRI suggest 2 closely related mechanisms could have accounted for the pain symptoms elicited during the attempted EDP. In the setting of shortened pedicular length, the transient increase in 
pressure within the epidural compartment following injection of a small amount of fluid could have compressed neural structures resulting in severe pain extending into the coccyx. The prominent deposition of epidural fat, which reduced the mean cross-sectional area of the thecal sac, could have contributed to loculation of the injected fluid that subsequently further compressed the thecal compartment resulting in acute pain. These possible mechanisms are also consistent with the observation that the patient did not experience pain when the dural puncture occurred during attempted epidural catheter placement, in that all fluid instilled upon loss of resistance was injected into the intrathecal compartment and not the epidural space. Furthermore, the reduced size of the epidural compartment could have contributed to the risk of a dural puncture, especially if the lateral aspects of the epidural space were transversed.

Whereas congenital lumbar spinal stenosis was described by early investigators nearly 70 years ago (5), little is known about the acute deleterious effects of epidural procedures in this unique patient population. In a recent retrospective review of 76 patients with juvenile degenerative disc disease, a subgroup of 13 patients were diagnosed with congenital lumbar spinal stenosis (6). All 13 patients were treated with a series of 3 lumbar epidural steroid injections which were performed without fluoroscopic assistance on a weekly basis. However, further clinical and procedural details were not reported, including pain symptoms elicited during performance of the epidural injection, volume of injectate, or supine versus prone patient positioning during the procedure. Long-term, 4 of 13 patients did not improve and required surgical decompression for refractory pain-related symptoms.

In our patient, the shortened pedicular length identified on MRI exemplified the cardinal radiographic finding of congenital lumbar spinal stenosis. In a prospective radiographic analysis that involved 20 participants with congenital spinal stenosis and 20 matched controls, pedicle length was shorter at levels L2 through L5 for individuals with congenital stenosis (7). Indeed, the mean pedicle length of levels L2 through L5 among patients with spinal stenosis was $6.0 \mathrm{~mm}$ (SD 0.31) compared to $9.0 \mathrm{~mm}$ (SD 0.18) for the control group (student's $t=36.6, \mathrm{P}<0.0001$ ). The mean pedicle length in our patient was $5.8 \mathrm{~mm}$. In the prospective radiographic analysis, the shortened pedicular length resulted in a concomitant reduction in the cross-sectional area of the lumbar spinal canal,
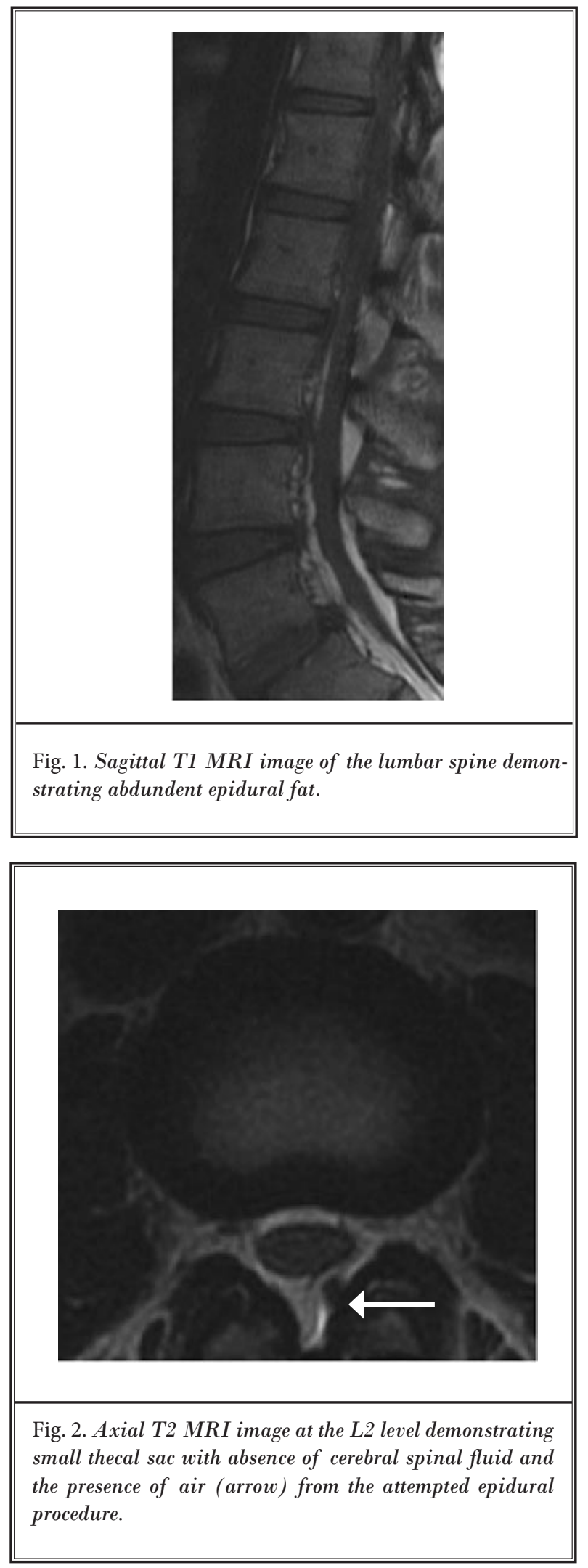
where the mean cross-sectional area of the stenosis group was $187 \mathrm{~mm} 2$ (SD 17.5) compared to $285 \mathrm{~mm} 2$ (SD 27.2) for the control group (student's $t=13.6, \mathrm{P}$ $<0.0001)$. In our patient, the mean cross-sectional area of the spinal canal was $223 \mathrm{~mm} 2$. When these patients require epidural interventions, the practitioner could consider performing these procedures at the lower levels of the lumbar spine, in that the neural axis diminishes in size as it terminates in the coccygeal region.

Similarly rare, epidural lipomatosis is an uncommon condition that can produce or contribute to symptoms of lumbar spinal stenosis (8). The condition is often associated with obesity, endocrinopathies, and chronic exposure to corticosteroids. Treatment is generally focused on resolving the underlying medical condition; however, idiopathic cases requiring surgical decompression have been reported (9). In our patient, prominent epidural fat contributed to a reduction in the mean cross-sectional area of the thecal sac (77 $\mathrm{mm} 2$ ). In a previous series of cadaveric studies, pres- sure changes within the thecal compartment of the lumbar spine were detected when the dural sac was constricted to a size less than $75 \mathrm{~mm} 2(10,11)$ These experimental findings provide support for our assertion that fluid loculation could have compressed the thecal sac to below the critical size of $75 \mathrm{~mm} 2$ resulting in acute spinal pain.

Performing an EBP for treatment of a post-dural puncture headache in a patient without a history of spinal pain or previous diagnostic imaging is a commonly encountered clinical scenario for the pain medicine specialist. The unique radiographic features of congenital spinal stenosis and epidural lipomatosis could predispose some patients with these unrecognized anatomical anomalies to develop acute spinal pain upon injection of a small amount of fluid into the epidural compartment. Unrecognized congenital lumbar spinal stenosis and epidural lipomatosis are important additions to the differential diagnosis of acute spinal during an EBP in previously asymptomatic patients.

\section{References}

1. Gleeson CM, Reynolds F. Accidental dural puncture rates in UK obstetric practice. Int J Obstet Anesth 1998; 7:242246.

2. Rutter SV, Shields F, Broadbent M, Popat RR. Management of accidental dural puncture in labour with intrathecal catheters: An analysis of 10 years' experience. Int / Obstet Anesth 2001; 10:177-181.

3. Turnbull DK, Shepherd DB. Post-dural puncture headache: Pathogenesis, prevention and treatment. Br J Anaesth 2003; 91:718-729.

4. Kalina P, Craigo P, Weingarten T. Intrathecal injection of epidural blood patch: A case report and review of the literature. Emerg Radiol 2004; 11:56-59.
5. Naderi S, Güclü B, Yurtsever C, Berk H. Dr. Ahmet Sarpyener: Pioneer in definition of congenital spinal stenosis. Spine 2007; 32:606-608.

6. Dimar JR, Glassman SD, Carreon LY. Juvenile degenerative disc disease: $\mathrm{A}$ report of 76 cases identified by magnetic resonance imaging. Spine J 2007; 7:332-337.

7. Singh K, Samartzis D, Vaccaro AR, Nassr A, Andersson GB, Yoon ST, Phillips FM Goldberg EJ, An HS. Congenital lumbar spinal stenosis: A prospective, controlmatched cohort radiographic analysis. Spine J 2005; 5:615-622.

8. Robertson SC, Traynelis VC, Follett KA, Menezes AH. Idiopathic spinal epidu- ral lipomatosis. Neurosurgery 1997; 41:68-74.

9. Min WK, Oh CW, Jeon IH, Kim SY, Park BC. Decompression of idiopathic symptomatic epidural lipomatosis of the lumbar spine. Joint Bone Spine 2007; 74:488-490.

10. Schönström N, Bolender NF, Spengler DM, Hansson TH. Pressure changes within the cauda equina following constriction of the dural sac. An in vitro experimental study. Spine 1984; 9:604607.

11. Schönstrm N, Hansson T. Pressure changes following constriction of the cauda equina. An experimental study in situ. Spine 1988; 13:385-388. 